\title{
CONDUTÂNCIA ESTOMÁTICA COMO INDICADOR DE ESTRESSE HÍDRICO EM FEIJÃO ${ }^{1}$
}

\section{ALEXSANDRA D. DE OLIVEIRA ${ }^{2}$, EDEMO J. FERNANDES ${ }^{3}$, TERESINHA DE J. D. RODRIGUES ${ }^{4}$}

\begin{abstract}
RESUMO: O objetivo do trabalho foi verificar os indicadores de estresse hídrico, bem como seu efeito na cultura do feijão, por meio da condutância estomática. O experimento foi realizado na Área Experimental de Irrigação da Universidade Estadual Paulista - Jaboticabal, no ano agrícola de 2000. Foram estudados quatro tratamentos de irrigação com níveis crescentes de ETm: (T1) ETm acumulada $=22 \mathrm{~mm}$; (T2) ETm acumulada = $33 \mathrm{~mm}$; (T3) ETm acumulada = $44 \mathrm{~mm}$; (T4) ausência de irrigação. Nas plantas com suprimento adequado de água, os maiores valores de condutância estomática ocorreram por volta do meio-dia solar, atingindo cerca de 159 e $174 \mathrm{mmol} \mathrm{m}^{-2} \mathrm{~s}^{-1}$, para T1 e T2, respectivamente, enquanto nos tratamentos $\mathrm{T} 3$ e $\mathrm{T} 4$, os maiores valores encontrados foram de 83 e $52 \mathrm{mmol} \mathrm{m} \mathrm{m}^{-2} \mathrm{~s}^{-1}$, respectivamente. A condutância estomática ao longo do ciclo apresentou valor máximo de $165 \mathrm{mmol} \mathrm{m}^{-2} \mathrm{~s}^{-1}$ para o tratamento T4, enquanto para T1 e T2 os valores máximos obtidos variaram de 179 a $183 \mathrm{mmol} \mathrm{m} \mathrm{m}^{-2}$. A temperatura da folha e a transpiração apresentaram estreita relação com a resistência estomática, enquanto a radiação fotossinteticamente ativa não diferiu entre os tratamentos.
\end{abstract}

PALAVRAS-CHAVE: Phaseolus vulgaris, parâmetros fisiológicos, irrigação.

\section{STOMATAL CONDUCTANCE AS AN INDICATOR OF WATER STRESS IN BEAN}

ABSTRACT: The objective of this work was to evaluate the water deficit and its effects on the beans crop by the stomatal conductance as water deficit indicator. This study was carried out at the Experimental Irrigation Station of the São Paulo State University - Jaboticabal, during the 2000 agricultural seasons year. Four irrigation treatments with growing levels of ETm were studied: (T1) accumulated ETm = $22 \mathrm{~mm}$; (T2) accumulated ETm $=33 \mathrm{~mm}$; (T3) accumulated ETm $=44 \mathrm{~mm}$; (T4) irrigation absence. In plants with appropriate supply of water, the stomatal conductance along the cycle presented maximum value around the solar noon, reaching 159 and $174 \mathrm{mmol} \mathrm{m}^{-2} \mathrm{~s}^{-1}$ for the treatment $\mathrm{T} 1$ and T2, respectivelly, and values of 83 and $52 \mathrm{mmol} \mathrm{m}^{-2} \mathrm{~s}^{-1}$ for the T3 and T4, respectivelly. The stomatal conductance along the cycle presented maximum value of $165 \mathrm{mmol} \mathrm{m}^{-2} \mathrm{~s}^{-1}$ for the treatment $\mathrm{T} 4$, while $\mathrm{T} 1$ and $\mathrm{T} 2$ obtained maximum values varied from 179 to $183 \mathrm{mmol} \mathrm{m} \mathrm{m}^{-2} \mathrm{~s}^{-1}$. The leaf temperature and the transpiration showed relation with the stomatal conductance while the photosynthetically active radiation (PAR) did not differ among the treatments.

KEYWORDS: Phaseolus vulgaris, physiological parameters, irrigation.

\section{INTRODUÇÃO}

A produção de feijão no Brasil está concentrada em três safras anuais, sendo a primeira denominada feijão das águas, cuja semeadura ocorre no período de setembro a outubro; a segunda

\footnotetext{
${ }^{1}$ Trabalho financiado pela Fapesp

${ }^{2}$ Eng ${ }^{\text {a }}$ Agrônoma, Doutoranda em Produção Vegetal, UNESP - Jaboticabal - SP, aduarte@ fcav.unesp.br

${ }^{2}$ Prof. Dr., Departamento de Engenharia Rural , UNESP, Jaboticabal - SP.

${ }^{3}$ Profa. Dra., Departamento de Biologia Aplicada, UNESP, Jaboticabal - SP.

Recebido pelo Conselho Editorial em: 8-5-2002

Aprovado pelo Conselho Editorial em: 17-12-2004
} 
safra ou feijão da seca, com semeadura entre janeiro e fevereiro, e a terceira safra ou feijão de inverno, com semeadura após maio. Devido à época de semeadura, das três safras, a terceira é a que mais necessita de irrigação como suplementação das necessidades hídricas da cultura (ROSTON \& BULISANI, 1988).

No Brasil, o Estado de São Paulo é um dos principais produtores de feijão de inverno; nesse, das 75,4 mil toneladas de feijão de inverno produzidas no Estado, na safra 1998-1999, 75\% foram provenientes da cultura de feijão irrigado (FERREIRA \& VEGRO, 1999).

Atualmente, apesar da qualidade tecnológica, não se observam ganhos substanciais na produtividade média brasileira de feijão, que é em torno de $600 \mathrm{~kg} \mathrm{ha}^{-1}$. Esse valor pode ser considerado muito baixo se comparado ao rendimento de $1.800 \mathrm{~kg} \mathrm{ha}^{-1}$ ou superior, que pode ser obtido com uso da irrigação tecnicamente conduzida. A implantação e a expansão da área irrigada por aspersão em São Paulo iniciou-se na década de 1980, ocorrendo, então, grande mudança tecnológica na cultura do feijoeiro (BULISANI et al., 1990).

As baixas produções têm sido atribuídas ao uso de cultivares pouco produtivas, incidência de pragas e doenças, e condições adversas do meio ambiente. Dentre elas, destaca-se o clima, importante para a semeadura de feijão, que é muito dependente da chuva; quando atípico com chuvas irregulares, acarreta decréscimo significativo na produção dessa cultura.

Como a maioria das culturas, o feijoeiro é sensível aos estresses hídricos, seja pelo déficit de água, seja pelo excesso. Assim, urge a necessidade de propiciar condições ambientais mais favoráveis para otimizar a produtividade da cultura.

O microambiente determina as respostas do feijoeiro e, a médio e longo prazos, muitos dos sintomas visuais de estresse hídrico são conseqüências de alterações nas respostas fisiológicas da planta, que podem ser detectáveis com antecedência. Segundo GUIMARÃES (1998), a intensidade dos danos provocados pelo estresse depende da duração, intensidade, freqüência e época de sua ocorrência. Em sementes, a deficiência hídrica provoca redução da germinação; no período vegetativo, ocorre, além de outros efeitos, a redução de área foliar; durante a floração provoca abscisão de flores, com conseqüente redução do número de vagens por planta e, no enchimento de grãos, reduz o número de grãos e peso de vagens.

Desse modo, caracterizam-se vários períodos críticos durante o ciclo do feijoeiro, em função da disponibilidade de água. Alguns trabalhos têm sido conduzidos para avaliar o efeito do estresse em vários períodos do ciclo da cultura. GARRIDO (1998) verificou, nas condições do Norte de Minas Gerais, que a deficiência de umidade no solo impediu a germinação de sementes. Observou, ainda, que o déficit de umidade, ocorrido no início e no final da floração ou no início da formação e crescimento das vagens, provocou reduções de 16\%; $42 \%$ e $58 \%$ na produção, respectivamente.

A condição hídrica das plantas está muito relacionada aos processos fisiológicos de importância para o vegetal. Processos como transpiração, fotossíntese, respiração e crescimento são muito influenciados pelas mudanças ocorridas no estado hídrico das folhas (HSIAO, 1973).

VIEIRA et al. (1989), trabalhando com duas cultivares de feijoeiro (Aroana 80 e Aeté 3), suspenderam a irrigação por um período de 17 dias, verificando que os valores da resistência estomática foram maiores na face superior que na inferior, com valores mínimos de 6 e $2 \mathrm{~s} \mathrm{~cm}^{-1}$, respectivamente, em ambas as cultivares.

SIONIT \& KRAMER (1976), estudando duas variedades de soja e duas de girassol desenvolvidas em ambientes controlados e submetidas a estresse hídrico, verificaram que a superfície adaxial tinha resistência mais alta do que a superfície abaxial, alcançando valores máximos em torno 
de $0,7 \mathrm{~s} \mathrm{~m}^{-1}$ para plantas de soja e valores similares para plantas de girassol, ocorrendo morte foliar quando a resistência alcançou valores de aproximadamente $0,5 \mathrm{~s} \mathrm{~m}^{-1}$.

KANEMASU \& TANNER (1969) e HSIAO (1973) relataram que, assim que o potencial de água do solo permaneceu acima de um valor crítico, que depende de cada espécie vegetal, o balanço hídrico interno da planta foi afetado apenas pelas variáveis atmosféricas. Em geral, esses estudos mostram grandes flutuações diárias, com reduções do potencial hídrico foliar e da turgescência durante a manhã, com posterior aumento após as 14 horas (GARRIDO, 1998).

A manutenção da temperatura foliar igual ou ligeiramente inferior à temperatura do ar comprova a capacidade de refrigeração das diversas cultivares ou espécies, via transpiração, no intuito de manter a planta protegida das faixas térmicas muito elevadas. Esse é um comportamento desejável e foi observado em várias espécies vegetais (LUDLOW \& MUCHOW, 1990). Também, foi sugerido que o comportamento da temperatura foliar em relação à temperatura do ar pode ser usado como indicador da condição hídrica da planta, o qual, devidamente obtido, pode ser utilizado como indicador do momento de irrigar (MILLAR, 1972).

Em valores de potencial hídrico foliar maiores que -1,2 a -1,0 MPa, considerados como críticos em feijoeiro, tem sido observado comportamento discrepante da condutância estomática (KANEMASU \& TANNER, 1969; HSIAO, 1973).

Existem poucos dados fisiológicos sobre o efeito da deficiência hídrica imposta de forma contínua. Assim, o objetivo do trabalho foi verificar os indicadores de estresse hídrico, bem como seu efeito na cultura do feijão.

\section{MATERIAL E MÉTODOS}

O experimento foi conduzido na Área Experimental de Irrigação da UNESP, Câmpus de Jaboticabal - SP. As coordenadas geográficas são $21^{\circ} 15^{\prime}$ de latitude sul, 48 $18^{\prime}$ de longitude oeste e altitude de $595 \mathrm{~m}$. O solo da área experimental foi classificado como Latossolo Roxo eutrófico (ALOISI \& DEMATTÊ, 1974), A moderado, textura argilosa, relevo suave ondulado. Os dados climatológicos do período experimental encontram-se na Tabela 1.

TABELA 1. Dados climatológicos obtidos durante o experimento.

\begin{tabular}{lcccc}
\hline Meses & Tar $\left({ }^{\circ} \mathrm{C}\right)$ & UR $(\%)$ & Precipitação $(\mathrm{mm})$ & ECA $(\mathrm{mm})$ \\
\hline Agosto & 21,3 & 59,6 & 45,9 & 187,12 \\
Setembro & 22,1 & 70,1 & 90,8 & 192,11 \\
Outubro & 26,6 & 55,1 & 15,6 & 315,02 \\
Novembro & 24,2 & 72,0 & 132,4 & 222,43 \\
\hline
\end{tabular}

Tar - temperatura média do ar; UR - umidade relativa média do ar; ECA - evaporação do tanque Classe A.

Foi utilizada a cultura do feijoeiro, cultivar Carioca, semeada em $1^{\circ}$ - $8-2000$, em espaçamento de 0,5m entre fileiras de plantas, com 18 sementes por metro. O sistema de irrigação utilizado foi por aspersão convencional. A área total do experimento foi de 1,0 ha, com área útil de cada parcela de 0,1 ha.

Os tratamentos foram definidos em função do nível de déficit hídrico por ocasião das irrigações:

Tratamento 1 (T1): irrigação efetuada quando a ETm acumulada = $22 \mathrm{~mm}$;

Tratamento 2 (T2): irrigação efetuada quando a ETm acumulada $=33 \mathrm{~mm}$;

Tratamento 3 (T3): irrigação efetuada quando a ETm acumulada = $44 \mathrm{~mm}$;

Tratamento 4 (T4): irrigação efetuada apenas para o estabelecimento da cultura. 
A evapotranspiração potencial (ETp) foi obtida pelos valores do tanque Classe A e do coeficiente de tanque $\left(\mathrm{K}_{\mathrm{p}}\right)$, enquanto a evapotranspiração máxima $(\mathrm{ETm})$ foi calculada pela seguinte equação:

$$
\mathrm{ETm}=\mathrm{K}_{\mathrm{c}} \mathrm{ETp}
$$

em que,

ETm - evapotranspiração máxima, mm, e

Kc - coeficiente da cultura (DOORENBOS \& KASSAM, 1994).

O monitoramento da cultura foi efetuado utilizando-se de porômetro "Steady State" LI-1600 da marca LICOR, com sensores apropriados. O déficit de pressão de vapor (DPV) foi calculado a partir dos dados de temperatura do ar e da umidade relativa, segundo metodologia adotada por REICHARDT (1990). A condutância estomática (Cs), transpiração (T), temperatura da folha (Tf) e radiação fotossinteticamente ativa (RFA) foram obtidas ao longo do dia (8 às $16 \mathrm{~h}$ ) em plantas com folhas totalmente expandidas e ensolaradas na face adaxial e abaxial. Com a finalidade de representar adequadamente as avaliações, quatro plantas foram tomadas ao acaso na época de cada medição; na superfície abaxial, foram tomadas invertendo a sua face, porém mantendo-a com a mesma orientação. As observações foram realizadas no período de 21-8 a 21-10-2000, cerca de cinco vezes por semana.

A radiação fotossinteticamente ativa (RFA) incidente sobre a superfície foliar foi medida por meio de sensor quântico LI-190-1 acoplado ao porômetro. Esse sensor mede o quantum de luz em $\mu \mathrm{E} \mathrm{s}^{-1} \mathrm{~m}^{-2}$ dentro da faixa de 400 a $700 \mathrm{~nm}$, no intervalo de 0 a $2500 \mu \mathrm{E} \mathrm{s}^{-1} \mathrm{~m}^{-2}$.

A condutância estomática foi obtida segundo a analogia da Lei de Ohm, por meio do somatório das condutâncias estomáticas em paralelo das duas faces de cada folha analisada, metodologia utilizada por SHARPE (1973) e SOJKA \& PARSONS (1983) referindo-se à equação abaixo:

$$
1 / \mathrm{Cs}=1 / \mathrm{c}_{\mathrm{AD}}+1 / \mathrm{c}_{\mathrm{AB}}
$$

em que,

Cs - condutância da cultura, mmol $\mathrm{m}^{-2} \mathrm{~s}^{-1}$;

$\mathrm{c}_{\mathrm{AD}}$ - condutância da superfície adaxial, e

$\mathrm{c}_{\mathrm{AB}}$ - condutância da superfície abaxial.

\section{RESULTADOS E DISCUSSÃO}

A condutância estomática (Cs) para a cultura do feijão está apresentada na Figura 1. Observa-se que os menores valores encontrados, em quase todo o ciclo, foram para o tratamento sem irrigação (T4), variando de 14 a $165 \mathrm{mmol} \mathrm{m}^{-2} \mathrm{~s}^{-1}$, enquanto os maiores valores observados foram no tratamento (T1) variando de 48 a $183 \mathrm{mmol} \mathrm{m} \mathrm{m}^{-2} \mathrm{~s}^{-1}$, no final do ciclo. Para os tratamentos (T2 e T3), que apresentam ordem crescente em estresse hídrico, existiram períodos coincidentes ao longo do ciclo, embora tenham predominado valores menores para o T3, que variou de 27 a $179 \mathrm{mmol} \mathrm{m}^{-2} \mathrm{~s}^{-1}$.

Apesar da interação de diversos fatores que atuam sobre os estômatos e, consequientemente, sobre a Cs, fica evidente o efeito do estresse hídrico sobre esse parâmetro, observando que o mesmo pode ser utilizado como indicador da deficiência de água.

Outro fator que contribuiu para a variação no comportamento estomático e transpiratório da planta, observada durante o dia, foi a variação do ângulo de exposição das folhas aos raios solares, um importante mecanismo de defesa das plantas, que opera exatamente em períodos de estresse hídrico, diminuindo a temperatura foliar e, conseqüentemente, a transpiração estomatal. 

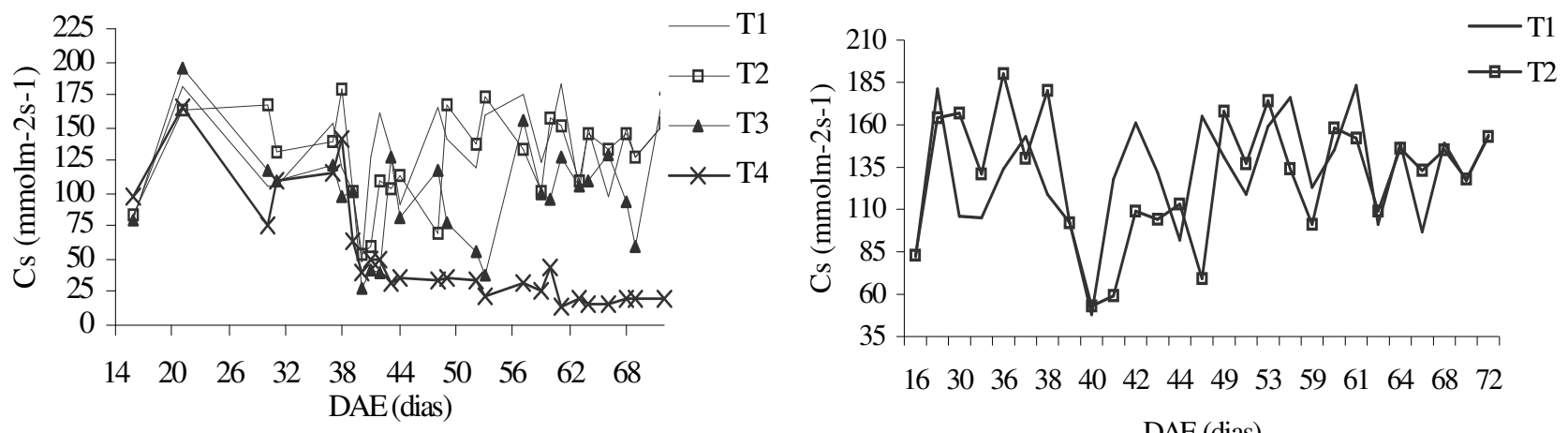

$\begin{array}{llllllllllllll}16 & 30 & 36 & 38 & 40 & 42 & 44 & 49 & 53 & 59 & 61 & 64 & 68 & 72\end{array}$

DAE (dias)

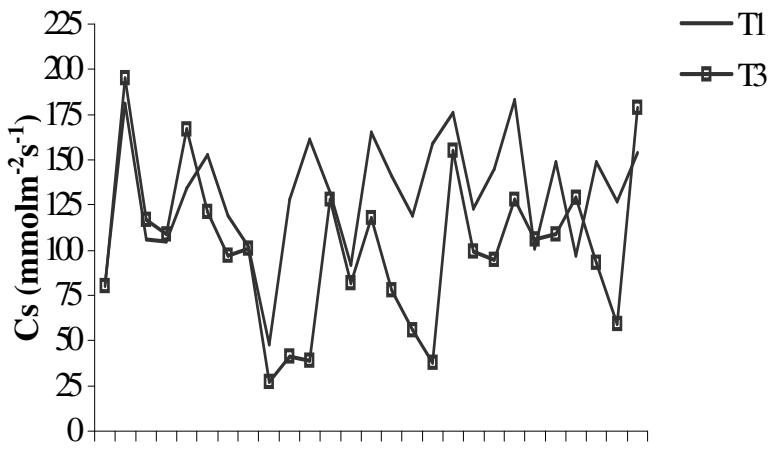

1630363840424449535961646872

$\mathrm{DAE}$ (das)

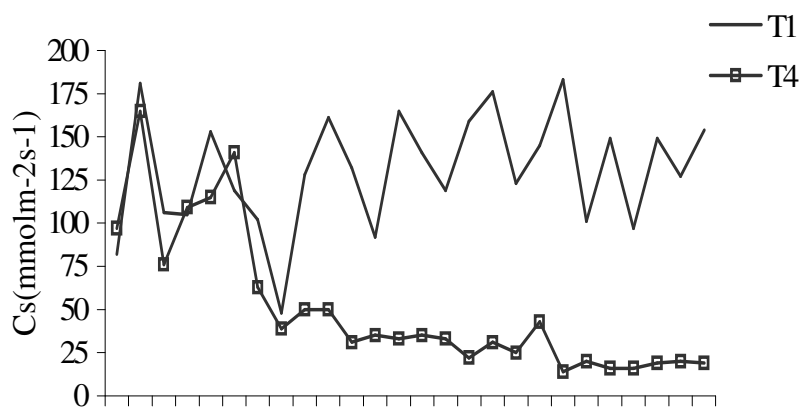

$\begin{array}{lllllllllllll}16 & 30 & 37 & 39 & 41 & 43 & 48 & 52 & 57 & 60 & 63 & 66 & 69\end{array}$

DAE(dias)

FIGURA 1. Valores médios diários da condutância estomática (Cs) ao longo do ciclo da cultura do feijão, submetida a quatro regimes de irrigação.

Os valores médios da condutância estomática ao longo de cada fase fenológica estão apresentados na Tabela 2. Constata-se que os ciclos de estresse hídrico impostos provocaram diminuição na condutância estomática no período da floração nos tratamentos T2, T3 e T4, enquanto na fase final houve decréscimo em T3 e T4. Os valores de Cs foram incrementados para T1 ao longo do ciclo e decrescentes para T4, chegando a decréscimo de aproximadamente $55 \%$ do crescimento vegetativo até a floração e de $63 \%$ do florescimento à maturação fisiológica, enquanto nos demais tratamentos não houve aumento. Tal comportamento era, de certa forma, esperado devido à condição hídrica do solo.

TABELA 2. Valores médios da Condutância estomática (Cs) em $\mathrm{mmol} \mathrm{m}^{-2} \mathrm{~s}^{-1}$, para diferentes estádios fenológicos, sob quatro tratamentos de irrigação.

\begin{tabular}{cccc}
\hline Tratamento & Crescimento Vegetativo & Florescimento & Maturação Fisiológica \\
\hline T1 & 121,60 & 122,00 & 140,00 \\
T2 & 147,00 & 103,00 & 141,00 \\
T3 & 133,60 & 80,70 & 108,00 \\
T4 & 127,60 & 69,80 & 25,40 \\
\hline
\end{tabular}

Para plantas menos estressadas (T1 e T2), é possível observar maior transpiração, chegando a atingir valores superiores a $11,5 \mathrm{e} 12 \mathrm{mmol} \mathrm{m}^{-2} \mathrm{~s}^{-1}$ por volta do meio-dia solar $(12 \mathrm{~h})$, enquanto T3 e T4 não ultrapassaram o valor médio de $4 \mathrm{mmol} \mathrm{m}^{-2} \mathrm{~s}^{-1}$ com valores superiores às $8 \mathrm{~h}$ (Figura 2A). 

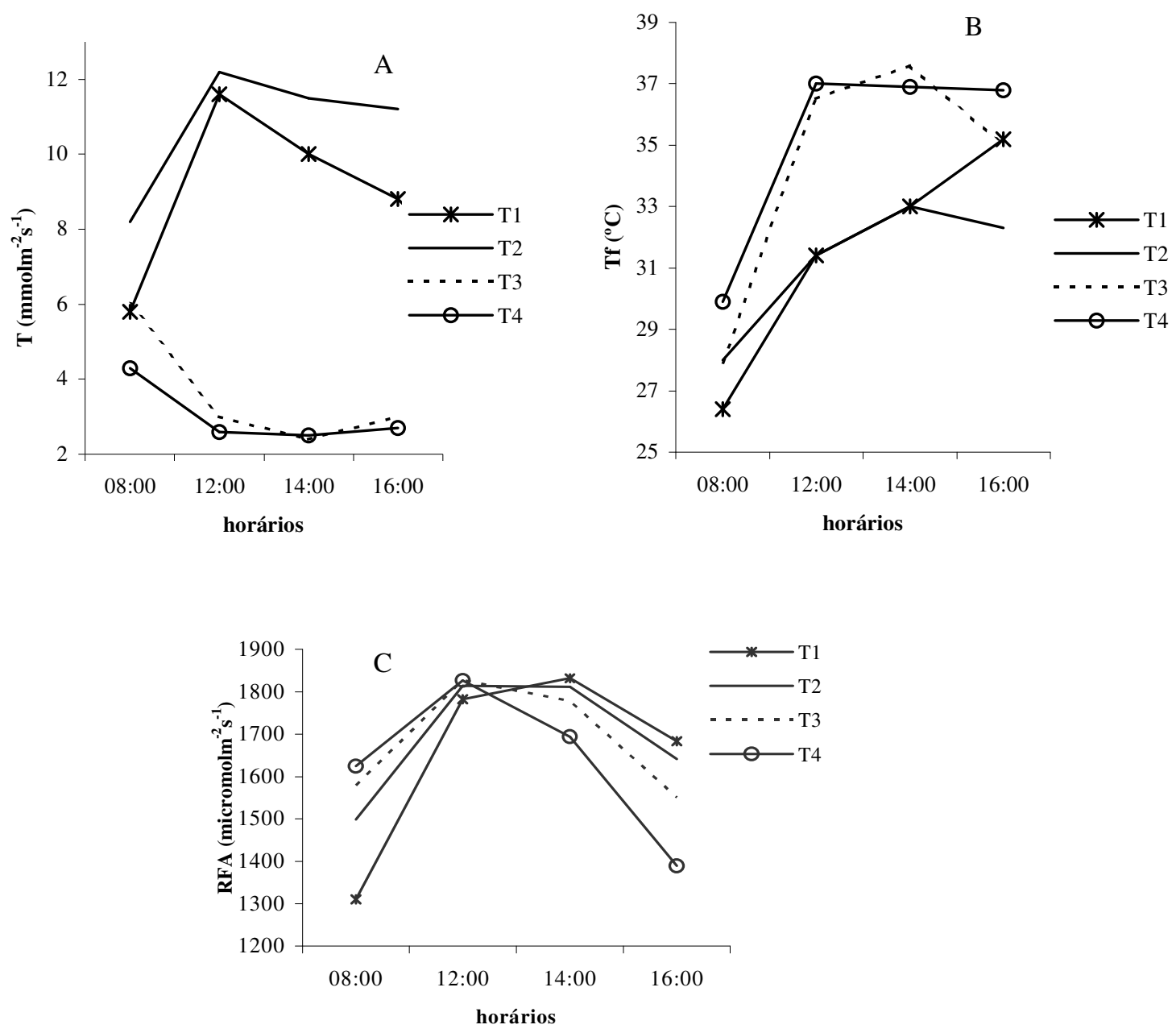

FIGURA 2. Valores médios da transpiração (T) (A), temperatura foliar (Tf) (B) e radiação fotossinteticamente ativa (RFA) (C) na cultura do feijão, em diferentes horários do dia, submetida a quatro regimes de irrigação.

SILVA et al. (1998), estudando a variação diurna da transpiração do amendoim irrigado, observaram que a máxima transpiração $\left(110 \mathrm{mg} \mathrm{H}_{2} \mathrm{O} \mathrm{m}^{-2} \mathrm{~s}^{-1}\right)$ foi obtida por volta do meio-dia para $\mathrm{o}$ tratamento que recebeu $700 \mathrm{~mm}$ por quatro dias e apenas às $16 \mathrm{~h} 30$ para o tratamento que recebeu $300 \mathrm{~mm}$ por quatro dias, atingindo transpiração de $12 \mathrm{mg} \mathrm{H}_{2} \mathrm{O} \mathrm{m}^{-2} \mathrm{~s}^{-1}$. Isso evidencia que, sob condições de deficiência hídrica, a abertura dos estômatos não ocorre somente em resposta à radiação solar, mas, sobretudo, em função do potencial hídrico do solo, conforme afirmaram autores como DUBË et al. (1974) e TURNER (1974).

A temperatura da folha para os tratamentos mais estressados (T3 e T4) atingiu valores máximos de $38^{\circ} \mathrm{C}$ ao meio-dia solar ou 12 e $14 \mathrm{~h}$, respectivamente, enquanto os demais atingiram valores máximos de $35^{\circ} \mathrm{C}$ às $16 \mathrm{~h}$ para $\mathrm{T} 1$, e $33^{\circ} \mathrm{C}$ às $14 \mathrm{~h}$ para T2 (Figura $2 \mathrm{~B}$ ).

A radiação fotossinteticamente ativa apresentou comportamento semelhante para todos os tratamentos, com valores ao redor de $1850 \mu \mathrm{mol} \mathrm{m} \mathrm{m}^{-2} \mathrm{~s}^{-1}$ (Figura 2C).

O curso horário da condutância estomática (Cs) na floração está apresentado na Figura 3. Comparando os tratamentos no dia 2-10-2000, verifica-se que T3 e T4 apresentaram seus maiores valores de 83 e $52 \mathrm{mmol} \mathrm{m}^{-2} \mathrm{~s}^{-1}$ às $8 \mathrm{~h}$, enquanto T1 e T2 apresentaram seus valores máximos de 159 e $174 \mathrm{mmol} \mathrm{m}^{-2} \mathrm{~s}^{-1}$ ao meio-dia solar, com posterior decréscimo para todos os tratamentos. No dia 
12-10-2000, não foi possível realizar a leitura das 8 h, em função de as folhas ainda estarem molhadas, impossibilitando o início das leituras, mas ao meio dia-solar as leituras foram iniciadas, observando-se valores máximos às $14 \mathrm{~h}$ para os tratamentos T2 $\left(118 \mathrm{mmol} \mathrm{m}^{-2} \mathrm{~s}^{-1}\right)$, T3 $\left(111 \mathrm{mmol} \mathrm{m}^{-2} \mathrm{~s}^{-1}\right) \mathrm{e}$ T4 $\left(23 \mathrm{mmol} \mathrm{m} \mathrm{m}^{-2}\right)$, enquanto T1 atingiu sua máxima condutância às $16 \mathrm{~h}\left(180 \mathrm{mmol} \mathrm{m} \mathrm{m}^{-2} \mathrm{~s}^{-1}\right)$. No dia 17-10-2000, as menores condutâncias foram observadas no T4 em todos os horários; para os tratamentos T1 e T2, seus comportamentos foram semelhantes ao longo do dia, e T3 apresentou maior variação após o meio-dia com acentuado decréscimo na Cs (de 93 a $72 \mathrm{mmol} \mathrm{m}^{-2} \mathrm{~s}^{-1}$ ). Resultados de PETERSEN et al. (1991) e BASCUR et al. (1985) com feijão, e SCHURR et al. (1992) com Heliantus annuus, confirmam essas observações. Segundo SILVA et al. (1998), quando a umidade do solo é baixa, os estômatos fecham-se antecipadamente pela manhã, uma vez que, nessa condição, a abertura dos estômatos não é função da energia incidente, e sim da disponibilidade hídrica da planta.

As variações da Cs observadas ao longo do período diurno (Figura 3) podem ser explicadas por uma série de fatores. Tais variações podem ser devido à sensibilidade à radiação solar que, segundo TURNER (1974), sob a condição de estresse, influencia a ação estomática, ao déficit de pressão de vapor d'água que atua como indicador do equilíbrio térmico entre a planta e o meio, além de ritmos endógenos em função da diminuição da água no solo. Essas observações são confirmadas pelos autores MEINZER et al. (1993) e TARDIEU \& DAVIES (1993), os quais estabeleceram relações entre o mecanismo de abertura e fechamento dos estômatos e diversos fatores do meio e da própria planta que atuam sobre os mesmos. Em função disso, as medições de condutância estomática, em geral, apresentam variabilidade acentuada.
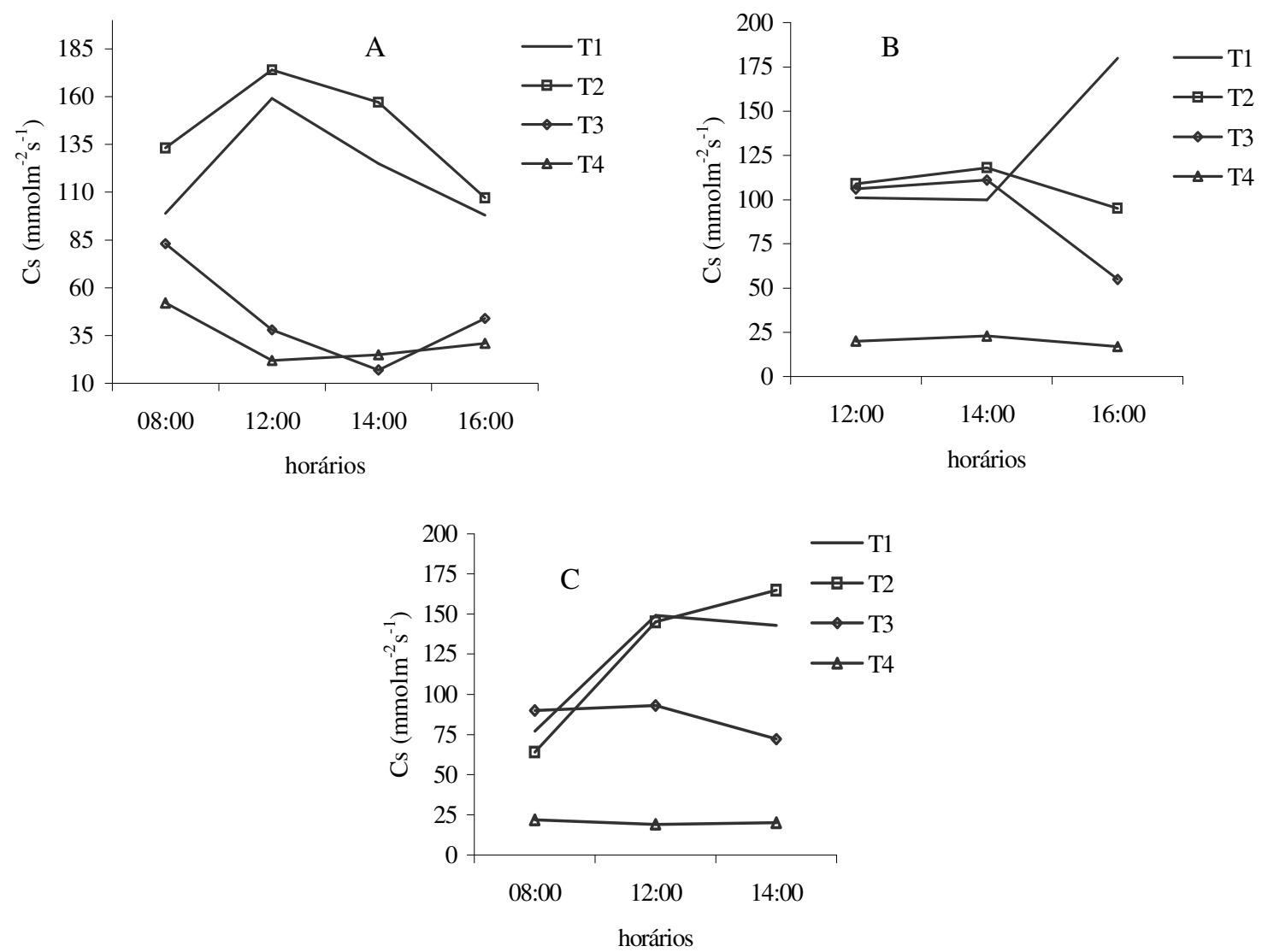

FIGURA 3. Valores da condutância estomática (Cs) para os dias 2-10-2000 (A), 12-10-2000 (B) e 17 10-2000 (C) ao longo do dia, respectivamente, com quatro regimes de irrigação.

A temperatura da folha apresentou valores que variaram de $29{ }^{\circ} \mathrm{C} \mathrm{a} 42{ }^{\circ} \mathrm{C}$, ao longo do ciclo da cultura, sendo observado que os tratamentos $\mathrm{T} 3$ e $\mathrm{T} 4$ foram os que apresentaram as maiores 
temperaturas foliares (Figura 4A). Os valores médios da transpiração ao longo do ciclo situaram-se entre 2 e $12 \mathrm{mmol} \mathrm{m}^{-2} \mathrm{~s}^{-1}$. Apenas para o T4, a partir de 44 dias após a emergência, houve decréscimo nos valores quando comparado aos demais tratamentos (Figura 4B). Na floração, a transpiração atingiu valores máximos de $12 \mathrm{mmol} \mathrm{m}^{-2} \mathrm{~s}^{-1}$ para os tratamentos $\mathrm{T} 1 \mathrm{e} \mathrm{T} 2$, ao meio-dia solar, e máximos de 8,5 e 3,5 $\mathrm{mmol} \mathrm{m}^{-2} \mathrm{~s}^{-1}$ para T3 e T4, respectivamente (Figura 4B).

A condição hídrica das plantas em relação aos demais tratamentos, principalmente para T3 e T4, mostrou que os diferenciais médios de temperatura da folha em relação à do ar foram crescentes à medida que progredia a deficiência hídrica, sendo de -3,20 para T1; -0,85 para T2; 0,76 para T3 e 3,27 para T4, concordando com resultados similares encontrados por PAZZETTI et al. (1992) para a cultura do feijão.

SAKAI et al. (1987), estudando o efeito do déficit hídrico sobre o comportamento estomático e a temperatura das folhas em feijoeiro, observaram que plantas sob déficit hídrico apresentaram maiores valores de resistência estomática e temperatura foliar. Além do efeito direto da resistência estomática à difusão de vapor de água de plantas de feijoeiro submetidas à deficiência hídrica, ocorre também diminuição da fotossíntese causada pelo aumento da temperatura da folha e conseqüente fechamento estomático, ocasionado pelo déficit hídrico (BERGAMASCHI et al., 1988), tornando escassa a disponibilidade de fotossintatos para o enchimento das vagens.
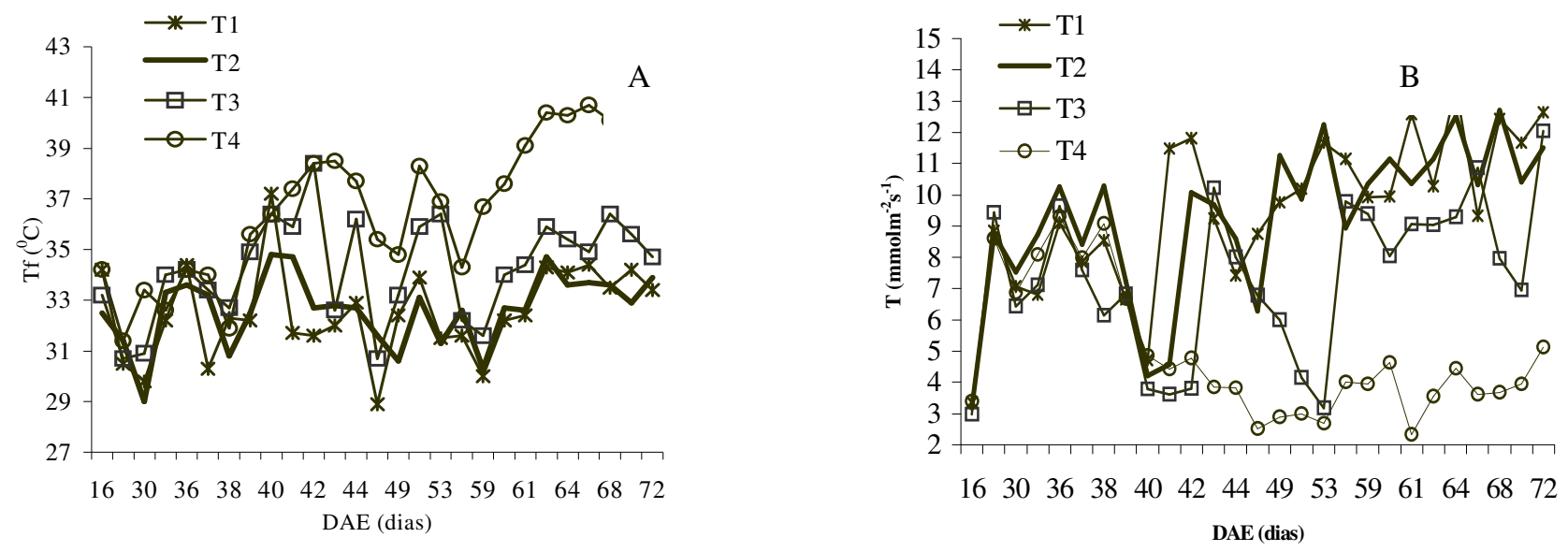

FIGURA 4. Valores médios diários ao meio-dia solar para temperatura foliar (Tf) (A) e transpiração (T) (B), com quatro regimes de irrigação.

\section{CONCLUSÕES}

Em plantas de feijão sob estresse hídrico, ocorreu acentuada diminuição da condutância estomática e da transpiração, proporcionalmente ao aumento desse estresse, e quanto mais intenso o estresse hídrico, maior a variabilidade horária e ao longo do ciclo.

Entre as variáveis estudadas, a temperatura da folha e a transpiração apresentaram estreita relação com a resistência estomática.

\section{REFERÊNCIAS}

ALOISI, R.R.; DEMATTÊ, J.L.T. Levantamento dos solos da Faculdade de Medicina Veterinária e Agronomia de Jaboticabal. Científica, Jaboticabal, p.123-36, 1974.

BASCUR, G.A.B.; OLIVA, M.A.; LAING, D. Termometria infrarroja en selección de genótipos de frijol resistentes a la sequía II. Bases Fisiológicas. Turrialba, San Jose, v.35, n.1, p.43-7, 1985. 
BERGAMASHI, H.; VIEIRA, H.J.; OMETTO, J.C.; ANGELOCCI, L.R.; LIBARDI, P.L. Deficiência hídrica em feijoeiro. I. Análise de crescimento. Pesquisa Agropecuária Brasileira, Brasília, v.23, n.7, p.733-43, 1988.

BULISANI, E.A.; ALMEIDA, L.D. Feijão: Phaseolus vulgaris L. In: JORGE, J.A.; LOURENÇÃO, A.L.; ARANHA, C. (Ed). Instruções agrícolas para o Estado de São Paulo. 5 ed. Campinas: Instituto Agronômico, 1990. p.94-5. (Boletim, 200)

DOORENBOS, J.; KASSAM, A.H. Efeito da água no rendimento das culturas. Campina Grande: UFPB, 1994. 306 p. (FAO - Estudos de Irrigação e Drenagem, 33)

DUBÉ, P.A.; STEVENSON, K.R.; THURTELL, G.W. Comparison between two inbred corn lines for diffusive resistances, photosynthesis and transpiration as a function of leaf water potential. Canadian Journal Plant Science, Ottawa, v.54, p.765-70, 1974.

FERREIRA, C.R.R.P.T.; VEGRO, C.L.P. Feijão. Informações Econômicas, São Paulo, v.29, n.7, p.101-3, 1999.

GARRIDO, M.A.T. Respostas do feijoeiro às lâminas de água e adubação nitrogenada. 1998. $205 \mathrm{f}$. Tese (Doutorado em Fitotecnia) - Universidade Federal de Lavras, Lavras, 1998.

GUIMARÃES, C.M. Efeitos fisiológicos do estresse hídrico. 1998. 205 f. Tese (Doutorado em Fitotecnia) - Universidade Federal de Lavras, Lavras, 1998.

HSIAO, T.C. Plant response to water stress. Annual Review of Plant Physiology, Palo Alto, v.4, p.519$70,1973$.

KANEMASU, E.T.; TANNER, C.B. Stomatal diffusion resistance of snap beans. I. Influence of leaf water potentials. Plant Physiology, Rockville, v.44, p.1547-52, 1969.

LUDLOW, M.M.; MUCHOW, R.C. A critical evaluation of traits for improving crop yields in waterlimited environments. Advances in Agronomy, San Diego, v.43, p.107-53, 1990.

MEINZER, F.C.; GOLDSTEIN, G.; HOLBROOK, N.M. Stomatal and environmental control of transpiration in a lowland tropical forest tree. Plant, Cell and Environment, Oxford, v.16, p.429-36, 1993.

MILLAR, A.A. Thermal regime of grapevines. American Journal of Enology and Viticulture, Davis, v.23, n.4, p.173-6, 1972.

NOGUEIRA, R.J.M.C.; SANTOS, R.C. dos. Alterações fisiológicas no amendoim submetido ao estresse hídrico. Revista Brasileira de Engenharia Agrícola e Ambiental, Campina Grande, v.4, n.1, p.41-5, 2000.

PAZZETTI, G.A.; CANO, M.A.O.; RESENDE, M. Aplicação da termometria por infravermelho a irrigação do feijoeiro (Phaseolus vulgaris L.): parâmetros fisiológicos. Revista Brasileira de Fisiologia Vegetal, Viçosa, v.4, n.1, p.27-31, 1992.

PETERSEN, K.L.; MORESHET, S.; FUCHS, M. Stomatal responses of field-grown cotton to radiation and soil moisture. Agronomy Journal, Madison, v.83, n.6, p.1059-65, 1991.

REICHARDT, K. A água em sistemas agrícolas. São Paulo: Manole, 1990.188 p.

ROSTON, A.J.; BULISANI, E.A. Feijão. CATI: Campinas, 1988.16 p. (Instrução Prática, 219)

SAKAI, E.; BULIZANI, E.; BRUNINI, O.; MURAMOTO, C.A. Efeito do déficit hídrico sobre o comportamento estomático e a temperatura das folhas em feijoeiro (cv.IAC-carioca 80). In: CONGRESSO BRASILEIRO DE AGROMETEOROLOGIA, 5., 1987, Brasília. Anais... Brasília: PRONI, 1987. p.370-6. 
SCHURR, L.; GOLLAN, T.; SCHULZE, E.D. Stomatal response to drying soil in relation to changes in the xylem sap concentrations of Heliantus annuus. I. Stomatal sensitivity to abscisic acid imported from the xylem sap. Plant, Cell and Environment, Oxford, v.15, p.561-7, 1992.

SILVA, L.C.; FIDELES FILHO, J.; BELTRÃO, E.M.; RAMANA RAO, T.V. Variação diurnal da resistência estomática à difusão de vapor de água em amendoim irrigado. Pesquisa Agropecuária Brasileira, Brasília, v.33, n.3, p.269-76, 1998.

SIONIT, N.; KRAMER, P.J. Water potential and stomatal resistance of sunflower and soybean subjected to water stress during various growth. Plant Physiology, Rockville, v.58, p.537-40, 1976.

SHARPE, P. J. H. Adaxial and abaxial stomatal resistance of cotton in the field. Agronomy Journal, Madison, v. 65, p.570-4. 1973.

SOJKA, R.E.; PARSONS, J.E. Soybean water status and canopy microclimate relationships at four row spacings. Agronony Journal, Madison, v.75, p.961-8. 1983.

TARDIEU, F.; DAVIES, W.J. Integration on hydraulic and chemical signaling in the control of stomatal conductance and water status of droughted plants. Plant, Cell and Environment, Oxford, v.16, p.341-9, 1993.

TURNER, N.C. Stomatal behavior and water status of maize, sorghum and tobacco under field conditions. II. At low soil water potential. Plant Physiology, Rockville, v.53, n.3, p.360-5, 1974.

VIEIRA, H.J.; BERGAMASCHI, H.; ANGELOCCI, L.R.; LIBARDI, P.L. Comportamento de duas variedades de feijoeiro sob dois regimes de disponibilidade hídrica no solo. II. Resistência estomática à difusão de vapor, densidade de fluxo transpiratório e potenciais da água na planta. Pesquisa Agropecuária Brasileira, Brasília, v.24, n.9, p.1045-53, 1989. 